SCORECARD

\section{Emoticons \\ These infuriating yet useful keystroke}

combinations have reached their silver jubilee. They were first used in 1982 by Carnegie Mellon University's Scott Fahlman, who proposed them as an aid to electronic communication :-)

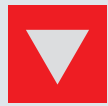

Conventional languages Meanwhile, $20 \%$ of the world's 7,000 languages are in danger of disappearing, with one going extinct every 14 days on average :-(

\section{NUMBER CRUNCH}

10 is the number of strands of Ludwig van Beethoven's hair that have been used to create three diamonds, one of which is to be auctioned on eBay.

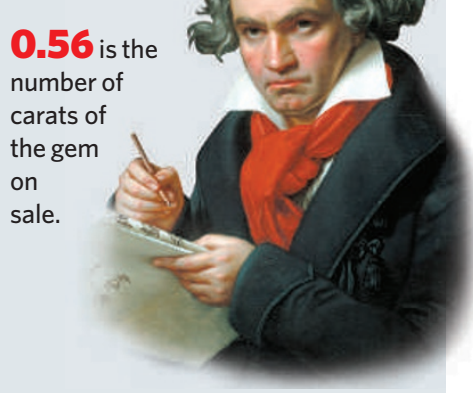

$\$ 500,000$ is the amount it is expected to fetch - meaning that you'll need a modern rock star's fortune if you want to be the owner.

\section{ON THE RECORD}

\section{“(The International Space Station is an orbital turkey.》” \\ Nobel-prizewinning particle} physicist Steven Weinberg is less than impressed with the achievements of manned spaceflight.

\section{OVERHYPED}

\section{Velociraptor}

Continuing the turkey theme, palaeontologists have announced that velociraptor - far from being fearsome or scaly - actually more closely resembled the traditional holiday poultry. Did Michael Crichton mislead us all?

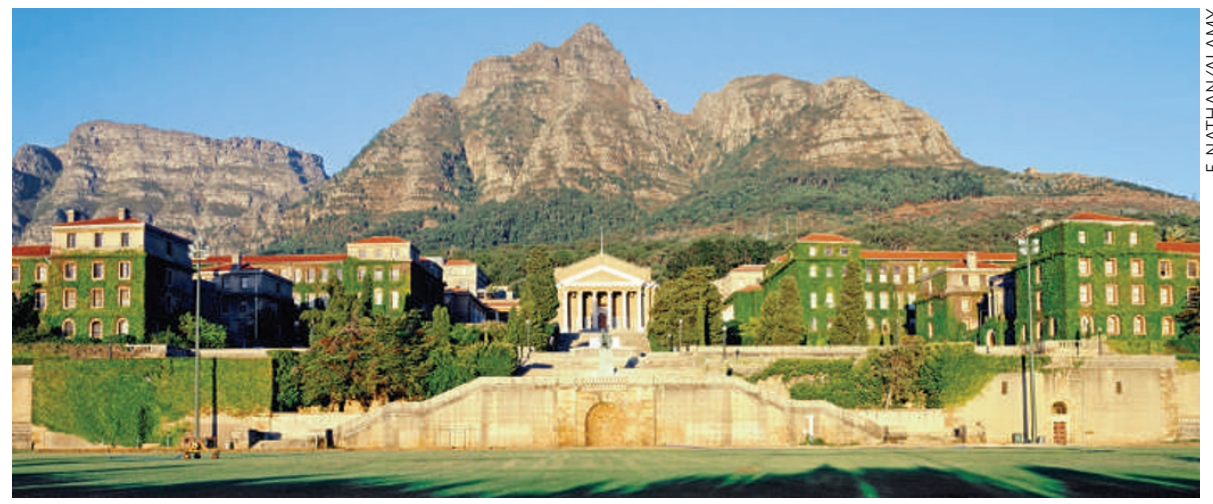

The University of Cape Town has received the lion's share of research positions from the government.

\title{
South African scheme
} lures in top talent

\section{CAPE TOWN}

South Africa's mission to create a globally competitive national academy of sciences reached another milestone last week with the announcement of 51 new research chairs. The South African Research Chairs Initiative, launched by the government in December 2006 , aims to create 210 research chairs by 2010 in a range of disciplines from nanophotonics to dignity jurisprudence.

The government hopes that the scheme will seduce foreign researchers to come to South Africa, as well as encourage the country's top researchers to stay and expatriates to return. Two-thirds of the 72 appointments made so far are people already working in South Africa, but the eventual aim is for $60 \%$ of the appointments to come from abroad. To redress the balance, the next round of awards is likely to be confined to applicants from outside the country, says Robin Drennan of South Africa's National Research Foundation, which administers the scheme.

But Cheryl de la Rey, deputy vice-chancellor for research at the University of Cape Town, says that the selection process makes it difficult to attract overseas candidates. "It's not easy to get people to move continents, and a problem with the current procedure is that it takes so long that some foreign-based candidates take up other offers. We must try to improve the turnaround time," she says.

The National Research Foundation's chief executive Mzamo Mangaliso says the selection process will be overhauled to speed it up without compromising quality. "We hope to empower our universities to recruit suitable candidates in a speedy and focused manner," he says.

Although 14 of the country's 22 universities have been awarded at least one chair, two-thirds of the appointments are concentrated at three universities: the University of Cape Town, the University of the Witwatersrand in Johannesburg and the University of Stellenbosch. Piet Steyn, Stellenbosch's director of research, says that this is unavoidable because a critical mass of researchers is needed as well as access to infrastructure such as experimental facilities and libraries - which are concentrated within relatively few regions of the country. The chairs, which will cost the state 170 million rand (US $\$ 24$ million) over the next five years, are a very positive and important intervention, Steyn says.

So far, around two-thirds of the incumbents are white, but the initiative aims to have $60 \%$ of the places filled by black researchers. One of the advantages of appointments from within the country, says de la Rey, is that universities are obliged, by the terms of the scheme, to fill the new chair-holder's previous post. This can be done at a more junior level, where it is often easier to diversify in terms of ethnicity and gender, she says.

Cancer biologist Iqbal Parker of the University of Cape Town, who is director of the newly established International Centre for Genetic Engineering and Biotechnology there, is delighted with his new research chair. $\mathrm{He}$ and Frank Brombacher, another researchchair holder, will head up the centre's first two research programmes - on non-communicable diseases, which are increasing in Africa, and the immunology of infectious diseases, respectively. Parker says that the main advantage of the scheme is that the research-chair positions incorporate awards of studentships, postdoctoral fellowships and running expenses for five years.

Michael Cherry 